\title{
Characterization of Novel Lignocellulosic Spinifex littoreus Fibers and their Composites
}

\author{
Milan Soosai $^{1}$, Christopher Thankian ${ }^{2}$, Winowlin Jappes Jebas Thangiah ${ }^{3}$, Rajini \\ Nagarajan $^{3,}$, Mayandi Kalimuthu ${ }^{3}$, Sikiru Oluwarotimi Ismail ${ }^{4}$, Faruq Mohammad \\ ${ }^{1}$ Department of Mechanical Engineering, Cape Institute of Technology, Levengipuram, \\ Tirunelveli 627114, Tamil Nadu, India \\ ${ }^{2}$ Department of Mechatronics Engineering, Kamaraj College of Engineering \& Technology \\ Vellakulam, Madurai dist-622701, Tamil Nadu, India \\ ${ }^{3}$ Centre for Composite Materials, Department of Mechanical Engineering, Kalasalingam \\ University, Krishnankoil, Virudhunagar 626 126, Tamil Nadu, India \\ ${ }^{4}$ Centre for Engineering Research, Department of Engineering, School of Engineering and \\ Computer Science, University of Hertfordshire, Hatfield, Hertfordshire AL10 9AB, England, \\ United Kingdom. \\ ${ }^{5}$ Surfactants Research Chair, Department of Chemistry, College of Science, King Saud \\ University, Riyadh 11451, Kingdom of Saudi Arabia.
}

*Corresponding author: Rajini N, E-mail: rajiniklu@gmail.com, Tel.: +919942139392; Fax: +914563289042

\begin{abstract}
This innovative work presents mechanical, physical and chemical characterization and analysis of newly extracted fiber from naturally resourced plant stem, named Spinifex littoreus fibers (SLF). This is a novel natural, biodegradable and sustainable reinforcement for an improved composite. Initially, the chemical constituents of SLF, such as cellulose, lignin, moisture and wax content were studied. The raw SLF surfaces were modified by chemical treatment with sodium hydroxide $(\mathrm{NaOH})$, calcium hydroxide $\left(\mathrm{Ca}(\mathrm{OH})_{2}\right)$ and silane. A polyester matrix was reinforced with all the treated SLF, before the mechanical properties (tensile strengths) of the composites were determined. Among all the surface chemically treated SLF/polyester composite samples, the calcium hydroxide $\left(\mathrm{Ca}(\mathrm{OH})_{2}\right)$ treated sample exhibited the highest
\end{abstract}


tensile strength. Further microscopic examination was carried out to validate this result. Also, this analysis established the mechanism of failure of the tensile fractured composite samples, using scanning electron microscope (SEM), among other techniques.

Keywords: Cellulosic fiber, Spinifex littoreus fibers, XRD, FTIR, SEM, Tensile strength.

\subsection{Introduction}

Natural fibers have been considered as a better alternative to synthetic fiber. They have been widely used in composite materials as reinforcing agents. The world material scientist focuses on the utilization of cellulose fiber based polymer composite materials, considering environmental friendliness and the biodegradable properties of natural fibers ${ }^{[1]}$. In view of environmental concerns, the current materials' researchers focus on the fabrication of biodegradable plastic from available natural resources ${ }^{[2]}$. Wastages from several manufactured synthetic polymer-based items are non-biodegradable, causing white contamination of the environment and harm to the animal life $^{[3]}$. Researchers have embarked on a ceaseless investigation into commonly used man-made vitreous fibers for finding a preferable alternative. The natural fibers are best alternative to synthetic fibers. The availability of natural fibers, such as hemp, ramie, banana, coir, jute, curaua, sisal and kenaf have been considered as biodegradable and harmless replacements for glass fibers for the purpose of reinforcing polymer-based engineering components ${ }^{[4]}$. Further study on the mechanical, physical and chemical characteristic of natural fibers is essential. This is required to establish the suitability of natural fibers as reinforcements for polymer composites.

The rough surfaced natural fibers in a polymer matrix have resulted into an improvement in mechanical strength. The fiber morphology showed rough surfaces, which was

examined by scanning electron microscope $(\mathrm{SEM})^{[5]}$. The need for low-density eco-friendly composites has increased in the automotive, sheets, pipes, aerospace and building industries. 
However, natural plant fibers have some drawbacks. These limitations include, but are not limited to, low-temperature degradation, poor chemical resistance and the capability of absorb more water (hydrophilicity), poor wettability and weak interfacing bonding with polymer materials during the fabrication of composite ${ }^{[6]}$. Several chemical treatment such as alkali, silane and acetylation are used for surface modification of fibers. The surface of natural fibers has been improved by reducing their hydrophilic nature during chemical treatment process. For instance, chemically treated natural fiber had a better wettability, bonding to the polymer and hence provided better mechanical property ${ }^{[7-11]}$. The chemical resistance properties of composites has been improved due to hydrophilic behavior of the lingo cellulosic and swelling behavior properties of the composites, depended on the fiber surface roughness. These properties were improved through the surface modification of the fiber ${ }^{[12]}$. To alter the properties of the natural bio-fibers in terms of cost effectiveness and time utilization, microwave irradiation was an efficient method through surface modification. For instance, hibiscus sabdariffa bio fibers recorded an increased thermal stability of its fibers ${ }^{[13]}$. The mechanical property (strength) of surface treated natural fiber reinforced polymer composites was improved with aid of various chemical treatment processes on the natural fiber reinforcement $^{[14-16]}$. Treatment of natural fiber under $\mathrm{NaOH}$ naturally removed the surface impurities on empty fruit bunch fibers. This process enhanced the thermal stability of the natural fiber ${ }^{[17]}$. Alkali and acetylation treatments on data palm fiber showed a better improvement in surface morphology with high groves in the fiber surface. Consequently, there was a significant improvement on the tensile strength of the composite ${ }^{[18]}$. Bachitara et al. reported that the alkaline treatment improved the interfacial bonding between the fiber and matrix, caused a modification on the surface of the fiber ${ }^{[19]}$. The change in surface of fiber has enhance some properties, such as moisture absorption, chemical resistance and water uptake. With the surface silane treatment on Saccaharumcilliare fibers, the physicochemical properties 
of the natural fibers was improved ${ }^{[20]}$. Rout et al. observed that the moisture absorption of a composite was lower on the surface morphology of the fiber through chemical treatment compared to the untreated fiber ${ }^{[21]}$. To minimize the hydrophilic nature of the fibers, chemical treatment was one of the essential methods, which significantly increased the fiber-matrix adhesion bonding. The surface modification improved the mechanical strength of the fiber ${ }^{[22]}$. Mathur et al. ${ }^{[23]}$ fabricated sisal, jute and coir fibers as reinforcements of composites for construction materials purpose. Arrakhiz et al. ${ }^{[24]}$ reported that chemically treated fiber composites showed a better mechanical properties, such as tensile, flexural and torsional, when compared with neat polypropylene composite. Rao et al. ${ }^{[25]}$ studied the surface modified natural elephant grass fibers. A polymer matrix was reinforced with this fiber to fabricate the polymer composite materials. They studied the mechanical properties and the results obtained showed an increased tensile property after chemical treatment. Obi et al. ${ }^{[26]}$ produced natural composites using leaf sheath of the coconut tree as a reinforcement. They evaluated the results of chemically treated and untreated composites. Kiruthuika et al. ${ }^{[27]}$ investigated chemically treated and untreated banana plant fibers and their tensile properties were examined. Summarily, based on various studies, the chemically treated natural fibers were more favourable and compactible with polymer matrix to obtain better mechanical bonding and strength. From aforementioned natural fibers and their corresponding composites, it is evident that there is no work on Spinifex littoreus fiber reinforced polymer (especially, unsaturated polyester) composites.

Hence, this innovative paper extensively provides mechanical, physical and chemical properties of newly identified Spinifex littoreus fibers (SLF). Lignin, cellulose, wax, hemicellulose and moisture composition in the SLF were discovered and evaluated. The results obtained were further analyzed by using effective techniques, such as Fourier Transform Infrared and X-ray diffraction. Most importantly, this is the first investigation into processing 
SLF as reinforcement in a polymer matrix. Different chemical treatments were applied on SLF surfaces. Each variety of chemically treated SLF was used for preparing separate composite plates. The tensile strength of treated SLF composites was determined through mechanical testing machine and compared with untreated SLF composites. The optimal surface chemical treatment of short SLF/polyester composites was predicted based on better tensile strength.

\subsection{Materials and Methods}

\subsection{Fiber Extraction Method}

Spinifex littoreus, popularly called Ravan's mustache or beach Spinifex littoreus is considered as a perennial grass with incredible stolon forming stems. Spinifex littoreus fibers (SLF) were collected from the seashore in Kanyakumari district, Tamilnadu (Fig. 1). These plants have grown up to $80-150 \mathrm{~cm}$ long with many interlinked branches and it has $1.2-1.5 \mathrm{~cm}$ wide. The long stem of the plant was sized using sharp knife edges. The sized stem plants were immersed in water for a week and were subjected to further microbial degradation process ${ }^{[28]}$. The dirt and other foreign materials of the Spinifex plant were cleaned with water. Then, a hammering force was applied to remove left-over flush on the fibers. Finally, the separated fibers were dried in room temperature.

\subsection{Polyester Matrix}

The SLF/polymer composite was fabricated using isophthalic unsaturated polyester resin as a matrix $^{[29-30]}$. The main reasons behind the choice of the polyester as a matrix include low cost and ease of accessibility/availability in the commercial market. A methyl ethyl ketone peroxide (MEKP) curing agent was used and cobalt naphthenate was utilized with resin. These chemicals were procured from New Emperor, Nagercoil, India.

\subsection{Characterization of Spinifex littoreus Fiber}




\subsubsection{Physical Analysis}

The single fiber tensile strength of SLF was performed using INSTRON (5500R) Universal testing machine. The tensile strength of SLF was tested for various gauge length of $10 \mathrm{~mm}$ to $40 \mathrm{~mm}$. The results obtained are presented Table 1. During single filament test on the SLF, the machine crosshead speed was maintained as constant of $0.1 \mathrm{~mm} / \mathrm{min}$ in accordance with the ASTM D3822-07 standard throughout the period of tensile test. An ambient temperature of 27 ${ }^{\circ} \mathrm{C}$ with a relative humidity of $68 \%$ were set for all the tests.

\subsubsection{Chemical Analysis}

The chemical constituents, namely cellulose, lignin and hemicelluloses of Spinifex littoreus were determined by applying standard test methods ${ }^{[4]}$. The density and wax contents were calculated using liquid immersion test toluene and standard protocol, respectively ${ }^{[31]}$. The specimen was kept in a hot air oven at $104{ }^{\circ} \mathrm{C}$ for 4 hours. This was necessary to determine the presence of moisture on the fiber surface. The ash present was examined in accordance with the ASTM E1755-61 standard ${ }^{[32,33]}$.

\subsubsection{X-Ray Spectra}

Fine-grained SLF were exposed to X-ray spectra in order to identify the crystalline index and crystalline size. It was refined using a Riguku X-ray diffractometer D/Max Ultima III with an $\mathrm{X}$-ray tube creating monochromatic $\mathrm{CuK} \alpha$ radiation, for $2 \theta$ range from $10^{\circ}$ to $80^{\circ}$ and a scan speed of $5^{\circ} \mathrm{min}^{-1}$.

\subsubsection{Fourier Transform Infrared Spectra}

A Perking Elmer Spectrum RXI Spectrometer was used for obtaining Fourier transform infrared spectra (FTIR) spectrum of the SLF. During testing, a scan rate of 32 scans per minute and a determination of $2 \mathrm{~cm}^{-1}$ in the wavenumber region of $500-4000 \mathrm{~cm}^{-1}$ were obtained ${ }^{[34]}$ 


\subsubsection{Scanning Electron Microscope}

The SEM machine model JOEL M-6390 was used to analyze the surface morphology of the SLF and also investigate the fracture morphology of SLF/polyester composites. During test, the SEM machine was set to an accelerated voltage of $10 \mathrm{kV}$. The specimen was glazed with the platinum layer to avoid the charging effects from electron beam during the diagnosis.

\subsubsection{Thermogravimetric Analysis (TGA)}

Thermal degradation behavior of the raw SLF and chemically treated SLF were measured, using TGA technique. The Jupiter Simultaneous thermal analyzer (Model STA 449 F3, NETZSH, German) machine was used to record the thermograms of SLF. The temperature range was set between $28{ }^{\circ} \mathrm{C}$ and $800{ }^{\circ} \mathrm{C}$ at a heating rate of $10{ }^{\circ} \mathrm{C}$ per minute, under nitrogen atmosphere conditions $^{[28]}$.

\subsection{Fiber Treatment, Fabrication and Testing of Composites}

\subsubsection{Fiber Treatment}

The chemical treatment was carried out on the outer surface of fiber effectively to decrease the hydrophilic nature of SLF. The outer surfaces of SLF were changed from smooth to rough surfaces. This aided better interfacial bonding between SLF and the matrix. The raw SLF was subjected to different forms of surface treatments, using $\mathrm{NaOH}, \mathrm{Ca}(\mathrm{OH})_{2}$ and silane. The concentrations of these alkali were prepared to be $10 \mathrm{wt} \%$ to the solution. All the chemical treatments of SLF were done separately. The fiber immersed time was considered for 1 hour. After this process, the fiber was thoroughly washed with fresh water. Finally, the water molecules were removed from the surfaces of SLF fibers, using a hot air oven at $70{ }^{\circ} \mathrm{C}$ for 3 $\operatorname{hours}^{[14]}$. 


\subsubsection{Fabrication of Composite Plate}

The SLF/polyester composite was fabricated with a dimension of $300 \mathrm{~mm}$ x $125 \mathrm{~mm}$ x $3 \mathrm{~mm}$. A compression molding technique was used. The length of fiber ranged from 80 to $120 \mathrm{~cm}$. The weight percentage of fibers was taken as $40 \mathrm{wt} \%$ during fabrication of both chemically treated SLF/polyester composites and untreated counterparts ${ }^{[35]}$. Before fabrication of the composites, the natural fibers were dried in a room temperature to remove the water molecules from the fiber surfaces. This process took a week. After the drying process, the fiber weight was measured as $52 \mathrm{~g}$ in digital balance to obtain $40 \mathrm{wt} \%$ of fiber reinforced with polymer matrix. During fabrication of the untreated composites, all the single fibers were changed into a mat, using a randomly integrated fashion by subjecting them to a pre-compression process before composites were formed. The randomly oriented fiber mat structure was implanted inside the mold cavity, followed by the flow of the resin over the fiber surfaces, to ensure a complete wetting. Before pouring the mixed resin to compression mat, the polyester resin was taken in a glass vessel firstly, then curing agent was added to the vessel, such as MEKP and cobalt naphthenate. This combination was thoroughly mixed until it became a homogenous resin mixture. After pouring of resin to fibers, then the die was closed with top cover and placed on a compression-molding machine. High pressure was applied after a complete closure of the mold. The high compression pressure was maintained for 6 hours. After, the composites was carefully ejected from the mold. The samples were dissected to the needed dimensions, as required for mechanical testing. A similar process was adopted and repeated for the treated SLF reinforced polyester composites, before further tests were performed.

\subsubsection{Mechanical Testing of Composite}

According to ASTM-D3039 standards, tensile test was performed on SLF/polyester composites $^{[35,36]}$. The tensile specimens were prepared using a precious stone tipped cutter with dimensions of $200 \mathrm{~mm} \times 20 \mathrm{~mm} \times 3 \mathrm{~mm}$. An FIE universal testing machine, UTE-40 model 
with a capacity of $400 \mathrm{kN}$, a crosshead speed of $1.0 \mathrm{~mm} / \mathrm{min}$ and a gauge length of $100 \mathrm{~mm}$ were used to conduct the mechanical test on the composites.

\subsection{Results and Discussion}

\subsubsection{Physical and Tensile Properties of SLF}

The strength of SLF depends on natural formation of cell wall structure, size and presence of chemical compositions. These compositions determine the mechanical characteristics of the SLF. The cell walls structures, chemical constituents and compositions vary for different SLF. This is the reason for obtaining different tensile strengths for various natural SLF. The range of tensile strength of SLF was predicted by using single filament test. Tests were conducted for various lengths, ranging from $10 \mathrm{~mm}$ to $40 \mathrm{~mm}$ in the order of $10 \mathrm{~mm}$ using an INSTRON (5500R) universal testing machine (UTM). The single filament tensile strength results obtained for different lengths are presented in Table 1. A comparison of the tensile strengths of Spinifex littoreus fibers was carried out with other potential commonly used or popular stem/bast fibers, such as jute, flax and hemp. The tensile strengths range of flax, hemp and jute fibers are 3422000, 272-900 and 320-800 MPa, respectively. The tensile strength of SLF range was 240-380 MPa. Significantly, the strain to failure of SLF recorded higher value than other stem fibers,

such as veldt grape, Cyperus pangore $i^{[37,38]}$. In addition, an image pro software was used to determine the average fiber diameter, with samples taken in the longitudinal direction through the SEM (Fig. 2).

\subsubsection{Chemical Properties of SLF}

The chemical composition of plant fiber differs in peculiar proportions of the identical plant. The properties of chemical compositions for both treated and untreated SLF are depicted in Table 2. The high cellulose content of SLF enhanced its mechanical properties. From Table 2, 
the cellulose content of raw SLF was 76.20 wt \%, which was lower than treated SLF. The presence of cellulose content in treated SLF were $86.33 \mathrm{wt} \%, 82.44 \mathrm{wt} \%, 78.39 \mathrm{wt} \%$ for $\mathrm{Ca}(\mathrm{OH})_{2}$, silane and $\mathrm{NaOH}$, respectively. The content of hemicellulose in a fiber affected the mechanical properties of the fiber ${ }^{[38]}$. The hemicellulose content on the treated SLF was lower than the raw SLF. The raw SLF has $10.9 \%$ of hemicellulose, which reduced to $3.85 \%, 5.98 \%$ and $6.76 \%$ for $\mathrm{Ca}(\mathrm{OH})_{2}$, silane and $\mathrm{NaOH}$ respectively. This influenced the thermal stability and caused disintegration of microfibrils ${ }^{[39]}$. The raw Spinifex littoreus contained $18.54 \%$ lignin, $1.28 \%$ wax, $3.28 \%$ ash and $10.22 \%$ moisture contents. Natural fiber structure properties and surface morphology mainly depend on the presence of lignin content. The densities and lignin contents of all treated SLF were lower than the raw SLF, due to occurrence of chemical corrosion on the fiber surfaces. The surface interfacial fiber-matrix adhesion within the composite reduced with the presence of wax content. However, the wax presence on raw and treated Spinifex littoreus contains only a smallest percentage among of the aforementioned chemical compositions. The wax content of raw SLF was reduced from $1.28 \%$ to $0.66 \%, 0.69 \%$ and $0.88 \%$ for $\mathrm{Ca}(\mathrm{OH})_{2}$, silane and $\mathrm{NaOH}$, respectively. This was a negligible quantity. The reduction of wax and hemicellulose was one of the major advantages during fabrication of polymer composites $^{[40]}$. Therefore, the interfacial bond between raw Spinifex littoreus and the resin was not significantly influenced by the content of wax.

\subsubsection{FTIR Analysis}

The markings of FTIR spectra peaks were observed at 3333.32, 2917.49, 1633.74, 1371.00 and $1019.23 \mathrm{~cm}^{-1}$, as shown in Fig. 3(a). The strong peak at $3333.32 \mathrm{~cm}^{-1}$ was observed for both treated and untreated SLF, due to the presence of cellulose-I that caused the extension of carboxylic acid O-H, as represented by the peak at $3333.32 \mathrm{~cm}^{-1[20]}$. The peak at $2917.49 \mathrm{~cm}^{-1}$ indicated $\mathrm{C}-\mathrm{H}$ extension occurred due to the vibration of cellulose-I, this peak was present in both treated and untreated SLF. Another peak observed for treated and untreated SLF at 
$2849.22 \mathrm{~cm}^{-1}$ was the trademark band of the vibration $\mathrm{C}-\mathrm{H}$ of the $\mathrm{CH}$ and $\mathrm{CH}_{2}$ bunches in the compounds of cellulose and hemicelluloses. A noticeable peak was observed only for untreated SLF at $1633.74 \mathrm{~cm}^{-1}$, there was a presence of carboxyl stretching of C-O, which was an acetyl group in hemicellulose ${ }^{[28,41]}$. The peak at $1633.74 \mathrm{~cm}^{-1}$ was not present for treated SLF, due to the reduction of hemicellulose from the fibers and it was present only on the untreated $\mathrm{SLF}^{[28,42]}$. The moderate peak at $1371 \mathrm{~cm}^{-1}$ was present in both treated and untreated SLF, it can be attributed to strong acetyl $\mathrm{C}-\mathrm{O}$ with covered $\mathrm{C}-\mathrm{H}$ extension of phenols and ester. The small peak band was at $1019.23 \mathrm{~cm}^{-1}$, corresponding to alkoxy C-O ordinary bond causing vibration. The FTIR studies confirmed the reduction of hemicellulose, lignin and wax in the treated SLF and this study agreed with chemical analysis data.

\subsubsection{XRD Analysis}

Fig. 3(b) depicts an emblematic X-ray diffraction spectrum of raw and treated SLF. An uneven scatter was obtained in a single board feature for raw SLF initial peak at $2 \theta=15.55^{\circ}$ and treated SLF at $2 \theta=15.89^{\circ}, 15.97^{\circ}$, and $15.73^{\circ}$ degree for $\mathrm{Ca}(\mathrm{OH})_{2}$, silane and $\mathrm{NaOH}$, respectively. This showed the nature of semi-crystalline fiber. The intercalation of cellulose can be associated with the influence of hydroxyl and carbonyl groups, as revealed in the structure of the fiber. The crystalline index of raw and treated SLF was calculated using Eq. 1.

Crystallinity index $(\mathrm{CI})=\frac{I_{C}-I_{a m}}{I_{C}}$

The depths of crystalline and amorphous point are represented as $I_{c}$ and $I_{a m}$, respectively. Where $I_{a m}$ was obtained from first peak and $I_{c}$ denoted the peak intensity of second largest peak close to around at $2 \Theta=22^{\circ}$. The raw SLF rate of CI of $33.67 \%$ was greater than veldt grape fiber of $30.9 \%$ and lesser than Cyperus pangorei of $51 \%$, ramie of $58 \%$, Sansevieria cylindrical leaf of $60 \%$, and raffia textiles of $64 \%$, sisal of $71 \%$, flax of $80 \%$ and 
lastly, hemp of $88 \%^{[42-47]}$. From Fig. 3(b), it was evident that the CI values of all the treated SLF were higher than the untreated SLF, due to close packing cellulose chain ${ }^{[28]}$. The maximum CI value of SLF possessed on $\mathrm{Ca}(\mathrm{OH})_{2}$ treated fibers was $37 \%$, followed by $36.5 \%$ and $34.4 \%$ for silane and $\mathrm{NaOH}$ treated SLF, respectively. Thus, intercalation of cellulose can be attributed to the influence of hydroxyl and carbonyl groups obtained in the fiber structure ${ }^{[44]}$.

\subsubsection{Thermogravimetric Analysis of Spinifex littoreus Fiber}

Thermal stability of SL natural fibers was analyzed for raw and treated SLF, using TGA graph as shown in Fig. 4(a). It was observed that all the fiber strands showed the same trend of stages of degradation. Three stages of degradation were observed for raw and treated SLF. The same trend was observed in other natural fiber strands, investigated by other researchers ${ }^{[15,28]}$. In all the fiber strands, a minor degradation of mass loss was observed between the range of $30{ }^{\circ} \mathrm{C}$ to $165^{\circ} \mathrm{C}$. This occurred due to the removal of moisture or water molecules from the fiber surfaces, as observed. The degradation levels with their corresponding temperatures were listed in Table 3. It can be inferred that the raw fiber strand thermal degradation properties was lower than that of all the treated SLF. The highest thermal degradation was observed on $\mathrm{Ca}(\mathrm{OH})_{2}$ treated SLF, when compared with other treated SLF (NaOH and silane). From Fig. 4(a), it was noted that, the initial major degradation was observed at $247.7^{\circ} \mathrm{C}$ for $\mathrm{Ca}(\mathrm{OH})_{2}, 230.7{ }^{\circ} \mathrm{C}$ for $\mathrm{NaOH}$ and $239.3{ }^{\circ} \mathrm{C}$ for silane treated SLF. On the other hand, $223.6{ }^{\circ} \mathrm{C}$ value was noted for raw SLF strand. This degradation occurred due to the de-polymerization process of hemicellulose and lignin from the fiber surfaces ${ }^{[15,28]}$. The derivative thermograms of treated and untreated SLF were plotted in Fig. 4(b). And the corresponding inflection points of temperature values are listed in Table 3. The inflection point is a point where the degradation rate is maximum ${ }^{[28]}$. These points are noticeable on the derivative thermograms for both treated and untreated SLF. From these derivative themrograms, it can be observed that the chemically 
treated SLF has more thermal stability than raw SLF. This can be attributed to removal of amorphous components and presence of more $\alpha$ cellulose content on the treated SLF ${ }^{[15]}$.

\subsubsection{SEM Analysis of Spinifex littoreus Fiber}

Fig. 5 shows the electron microscopic images of various positions of raw SLF surface morphology in a longitudinal direction. One of the regions of the cell structures of SLF has a tiny honeycomb voids and the other has a smooth appearance. Waxy layer, rough surfaces and some impurities were also visible on the surfaces of SLF. The rough surfaces of the SLF enhanced the mechanical properties of the composites. Rough surfaces provided a better interfacial adhesion between the natural fiber surfaces and the matrix polymer. The surface of the fiber was unfinished with many slots and grooves, which improved wettability and stimulated bonding within the compositions of polymeric composites ${ }^{[45]}$.

\subsubsection{Tensile Strength of SLF/Polyester Composites}

Fig. 6 represents the tensile strengths of both treated and untreated SLF/polyester composite samples. The impact of fiber surface treatments on the tensile strength of short SLF/polyester composites is shown in Fig. 6. It was observed that the untreated SLF/polyester composites have a low tensile strength of $22 \mathrm{MPa}$, when compared with the treated counterparts. The tensile strengths of chemically treated SLF/polyester composites improved. This occurrence can be attributed to an increase in cellulose content and crystallinity of the treated SLF. In addition, this outcome has demonstrated the possibility of enhancing reinforcement of fibers by chemical treatments. During chemical treatment the hemicellulose, lignin and wax content was reduced from the fibers surfaces. Moreover, $\alpha$-cellulose content has greatly improved within the material ${ }^{[1,20,28]}$. Evidently, the mechanical properties of treated natural fiber based polymer composites increased, due to a larger quantity of cellulose present on treated natural

fiber filament, when compared with the untreated natural fiber ${ }^{[11,28]}$. It was interesting to 
observe that Spinifex littoreus based composites demonstrated a substantial increment in tensile strength.

Moreover, the tensile strengths significantly increased from 22 to 28, 28.5 and $30 \mathrm{MPa}$ for $\mathrm{NaOH}$, silane and $\mathrm{Ca}(\mathrm{OH})_{2}$ treated SLF/polyester composites, respectively, as depicted in Fig. 6. It was evident that $\mathrm{Ca}(\mathrm{OH})_{2}$ treated sample recorded the highest value of tensile strength, followed by silane and $\mathrm{NaOH}$ treated SLF reinforced counterparts. They all exhibited a higher tensile strength than the untreated SLF reinforced polymer composite. This can be attributed to best interfacial bonding between the $\mathrm{Ca}(\mathrm{OH})_{2}$ treated SLF surfaces and the polymer matrix. Also, there was a uniform stress transferred between the fiber and matrix under applied load. The $\mathrm{Ca}(\mathrm{OH})_{2}$ treated SLF/polyester composites showed 36\% increment in tensile strength, when compared with the untreated SLF composites. Moreover, the $\mathrm{Ca}(\mathrm{OH})_{2}$ treated SLF/polyester composites recorded an increment of $7 \%$ and $5 \%$, when compared with the $\mathrm{NaOH}$ and silane treated composite samples, respectively. The silane treated composite sample slightly increased in tensile strength more than the $\mathrm{NaOH}$ treated counterpart. The highest tensile strength of $\mathrm{Ca}(\mathrm{OH})_{2}$ treated SLF/polyester composites was compared with some natural fiber based polyester composites, such as Alfa/polyester, Tamarind/polyester and Palmyra/polyester composites materials ${ }^{[29]}$. It is commendable to have tensile strengths of $\mathrm{Ca}(\mathrm{OH})_{2}$ treated $\mathrm{SLF} /$ polyester composites better or higher than these natural fibers based polyester composites.

\subsubsection{Morphological Analysis of Spinifex littoreus Composites}

The SEM micrographs presented in Fig. 7 depicts the surfaces of SLF and their bonding with the polyester matrix; it shows interfacial adhesion between the matrix and the fiber surface at higher magnification factor. The interfacial adhesion is an essential factor that determmines the tensile strengths of composites. Additionally, the tensile fractured micrograph of the untreated SLF/polyester composite is shown in Fig. 7(a). The poor interfacial bonding and its resulted 
gap on the micrograph is also clearly shown in the same Fig. 7(a). Evidently, more broken SLF and intra-fiber detachment were also observed. These were more predominant with SLF.

Futhermore, the reason for the exhibition of poor tensile strength of untreated SLF/polyester composites could be traced to the presence of more voids, large interfacial gap, poor bonding at the interface of the fiber and $\operatorname{resin}^{[35,47-49]}$ Fig. 7(b) shows a strong coupling effects on the matrix and fibers, as observed surrounding the fibers. This ensured better interfacial bonding. The appearance of some tiny size and narrow surface gaps offered a higher load transfer and surface bonding between the fiber and the matrix. These were observed within the fractured surfaces of the $\mathrm{Ca}(\mathrm{OH})_{2}$ treated $\mathrm{SLF} /$ polyester composite samples. This could be the reason for obtaining best mechanical/tensile strength from this treated composites ${ }^{[35,50]}$.

\subsection{Conclusion}

Novel biodegradable, sustainable and environmental friendly Spinifex littoreus fibers have been newly developed, as a reinforcement for polyester polymeric composites. The tensile strength of SLF range was 240-380 MPa, which were comparetively higher than other natural fibers. The raw SLF has a density of $0.78 \mathrm{~g} \cdot \mathrm{cm}^{-3}$ and $\mathrm{Ca}(\mathrm{OH})_{2}$, silane and $\mathrm{NaOH}$ treated SLF have densities of $0.65,0.62$ and $0.63 \mathrm{~g} . \mathrm{cm}^{-3}$, respectively, which were lower than that of the synthetic fibers. Therefore, SLF can be used to fabricate lightweight composite materials. The FTIR and XRD results confirmed the removal of amorphous hemicellulose from the treated SLF. The treated SLF has a better thermal stability, when compared with the raw SLF. The SEM micrographs of the SLF established the presence of rougher and additional uneven surfaces along the length of fibers, that favoured the formation of a better surface interfacial bonding between the fiber and the matrix. The $\mathrm{Ca}(\mathrm{OH})_{2}$ treated SLF/polyester composite yielded best tensile strength when compared with the $\mathrm{NaOH}$ and silane treated and untreated 
counterparts. Hence, $\mathrm{Ca}(\mathrm{OH})_{2}$ has been identified as one of the suitable alkali for the surface treatments for SLF, among other natural fibers. Failure mechanisms such as fiber pullout, void and interfacial gaps in tensile fractured samples were observed on the untreated SLF/polyester composites. Conversely, a good interfacial bonding characterised with a few fractured fibers were observed on $\mathrm{Ca}(\mathrm{OH})_{2}$ treated $\mathrm{SLF} /$ polyester composites, using SEM analysis. Future work or study on the flexural and impact behaviors of the same combinations of polymeric composites is recommended.

\section{Acknowledgment}

The authors sincerely appreciate the Center for Advanced Materials, Department of Mechanical Engineering, Cape Institute of Technology, Kalasalingam University for their permission to carry out the preparation and testing of the composite samples.

\section{References}

[1] Sreenivasan V S, Ravindran D, Manikandan V, Narayanasamy R. Mechanical properties of randomly oriented short Sansevieria cylindrica fiber/polyester composites. Materials \& Design, 2011, 32, 2444-2455.

[2] Kommula V P, Obi R K, Shukla M, Marwala T, Varada R A. Physico-chemical,tensile, and thermal characterization of Napier grass (native African) fiber strands. International Journal of Polymer Analysis and Characterization, 2013, 18, 303-314.

[3] Jayaramudu J, Siva Mohan R G, Varaprasad K, Sadiku E R, Sinha R S, Varadarajulu A. Preparation and properties of biodegradable films from Sterculia urens short fiber/cellulose green composites. Carbohydrate Polymers, 2013, 93, 622-627.

[4] Sreenivasan V S, Somasundaram S, Ravindran D, Manikandan V, Narayanasamy R. Microstructural, physio-chemical and mechanical characterization of Sansevieria cylindica fibers - An exploratory investication. Materials \& Design, 2011, 32, 453-461. 
[5] Jawaid M, Alothman O N, Saba Y, Shekeil P M T, Abdul Khalil HPS (2014) Effect of chemical modifications of fibers on tensile properties of epoxy hybrid composites. International Journal of Polymer Analysis and Characterization, 2014, 19, 391- 403.

[6] Alida A, Shamsul B J, Mohamed A, Mazlee M N, Kamarudin H. Assessment of physical and mechanical properties of cement panel influenced by treated and untreated coconut fiber addition. Physics Procedia, 2011, 22, 263-269.

[7] Benitez A N, Monzon M D, Angulo I, Ortega Z, Hernandez P M, Marrero M D. Treatment of banana fiber for use in the reinforcement of polymetric matrices. Measurements, 2011, 46, 1065-1073.

[8] John M J, Anandjiwala R D. Recent developments in chemical modification and characterization of natural fiber-reinforced composites. Polymer Composites, 2007, 29, $187-207$.

[9] Obireddy K, Uma M C, Ramakrishna R K, Shukla M, Muzenda E, Varada R A. Effect of chemicals treatment and fiber loading on mechanical properties of borassus (Toddy Palm) fiber/epoxy composites. International Journal of Polymer Analysis and Characterization, 2015, 20, 612-626.

[10] Lee S H, Wang S. Biodegradable polymers/bamboo fiber biocomposite with bio-based coupling agent. Composites Part A: Applied Science and Manufacturing, 2006, 37, 8091.

[11] Singha A S, Thakur V K, Mehta I K, Shama Anjali, Khanna A J, Rana R K, and Rana A K. Surface modified Hibiscus sabdariffa fibers: Physico-chemical, thermal and morphological properties evaluation. International Journal of Polymer Analysis and Characterization, 2009, 14, 695-711. 
[12] Thakur V K, Singha A S, Thakur M K. Natural Cellulosic Polymers as Potential Reinforcement in Composites: Physicochemical and Mechanical Studies. Advances in Polymer Technology, 2012, 32, 427-435.

[13] Thakur V K, Singha A S. Rapid synthesis, characterization, and physicochemical analysis of biopolymer based graft copolymers. International Journal of Polymer Analysis and Characterization, 2011, 16, 153-164.

[14] Joseph K, Varghese S, Kalaprasad G, Thomas S, Prasannakumari L, Koshy P, Pavithran C. Influence of interfacial adhesion on the mechanical properties and fracture behaviour of short sisal fibre reinforced polymer composites. European Polymer Journal, 1996, 32(10), 1243-1250.

[15] Norul Izani M A, Paridah M T, Anwar U M K, Mohd Nor M Y, H'ng P S. Effects of fiber treatment on morphology, tensile and thermogravimetric analysis of oil palm empty fruit bunches fibers. Composites Part B: Engineering, 2013, 45, 1251-1257.

[16] Lee K E, Poh B T, Morad N, and Teng T T. Synthesis and characterization of hydrophobically modified cationic acrylamide copolymer. International Journal of Polymer Analysis and Characterization, 2008, 13 (2), 95-107.

[17] Chowdhury M N K, Beg M D H, Maksudur Khan R, Mina M F. Modification of oil palm empty fruit bunch fibers by nanoparticle impregnation and alkali treatment. Cellulose, 2013, 20, 1477-1490.

[18] Ahmad A, Ahmad M H, Khalifa A. Characterization of treated date palm tree fiber as composite reinforcement. Composites Part B: Engineering, 2009, 40, 601-606.

[19] Bachtiar D, Sapuan S M, Hamdan M M. The Influence of Alkaline Surface Fibre Treatment on the Impact Properties of Sugar Palm Fibre-Reinforced Epoxy Composites. Polymer - Plastics Technology and Engineering, 2009, 48, 379-383. 
[20] Vijay K T, Amar S S, Inderjeet K, Ramkumar P N, Yang L. Silane Functionalization Of Saccaharumcilliare fibers: Thermal, morphological, and physicochemical Study. International Journal of Polymer Analysis and Characterization, 2010, 15, 397-414.

[21] Rout J, Misra M, Tripathy S S, Nayak S K, Mohanty A K. The influence of fibre treatment on the performance of coir-polyester composites. Composites Science and Technology, 2001, 61, 1303-1310.

[22] Kabir M M, Wang H, Lau K T, Cardona F. Chemical treatments on plant-based natural fibre reinforced polymer composites: Anoverview. Composites Part B: Engineering, 2012, 43, 2883-2892.

[23] Mathur V K . Composite materials from local resources. Construction and Building Materials, 2006, 20, 470-477.

[24] Arrakhiz F Z, Malha M, Bouhfid R, Benmoussa K, Qaiss A. Tensile, flexural and torsional properties of chemically treated alfa, coir and bagasse reinforced polypropylene Composites Part B: Engineering, 2013, 47, 35-41.

[25] Rao K M M, Prasad A V R, Babu M N V R, Rao K M, Gupta A V S. Tensile properties of elephant grass fiber reinforced polyestercomposite. Materials Science, 2007, 42, $2666-2672$.

[26] Obi R K, Sivamohan R G, Uma M C, Varada R A, Madhusudhana R K. Structural characterization of coconut tree leaf sheath fiber reinforcement. Journal of Forest Research, 2010, 21, 53-58.

[27] Kiruthika A V, Veluraja K. Experimental studies on the physico-chemical properties of banana fibre from various varieties. Fibers and Polymers, 2009, 10, 193-199.

[28] Mayandi K., Rajini N, Pitchipoo P, Winowlin Jappes J T, Varada R A. Properties of Untreated and Chemically Treated Cissus Quadrangularis Natural Fibers and Their Composites With Polyester as the Matrix. Polymer Composites, 2018, 39, 876-886. 
[29] Thiruchitrambalam M, Shanmugam D. Influence of pre-treatments on the mechanical properties of palmyra palm leaf stalk fiber-polyester composites. Journal of Reinforced Plastics and Composites, 2012, 31, 1400-1414.

[30] Kalimuthu M, Nagarajan R, Batcha A A, Siengchin S, Anumakonda V R, Ayrilmis N. Mechanical property and morphological analysis of polyester composites reinforced with cyperus pangorei fibers. Journal of Bionic Engineering, 2019, 16, 164-174.

[31] Pearl I A. The chemistry of lignin. New York: Marcel Dekker, 1967, pp. 32-58.

[32] Conrad C M. Determination of wax in cotton fiber. A new alcohol extraction method. Industrial and Engineering Chemistry, Analytical Edition, 1944, 16, 745-748.

[33] Reddy N, Yang Y. Characterizing natural cellulose fibers from velvet leaf (Abutilon Theophrasti) stems. Bioresource Technology, 2008, 99, 2449-2454.

[34] Sreenivasan V S, Ravindran D, Manikandan V, Narayanasamy R. Influence of fiber treatments on mechanical properties of short Sansevieria cylindrical/polyester composites. Materials \& Design, 2012, 37, 111-121.

[35] Mayandi K, Rajini N, Pitchipoo P, Winowlin J J T, Varada R A. Mechanical performance of Cissusquadrangularis/polyester composite. Materials Today Communication, 2015, 4, $222-232$.

[36] Sathishkumar T P, Navaneetha K P, Shankar S. Tensile and flex-ural properties of snake grass natural fiber reinforced isophthallic polyestercomposites. Composites Science and Technology, 2012, 72, 1183-1190.

[37] Mayandi K, Rajini N, Pitchipoo P, Sreenivasan V S, Winowlin J J T, Alavudeen A. A comparative study on characterizations of Cissusquadrangularis and phoenix reclinata natural fibers. Journal of Reinforced Plastics and Composites, 2015, 34, 269-280. 
[38] Mayandi K, Rajini N, Pitchipoo P, Winowlin J J T, Varada R A. Extraction and characterization of new natural lingo-cellulosic fiber Cyperus pangorei. International Journal of Polymer Analysis and Characterization, 2016, 21, 175-183.

[39] Sathishkumar T P, Navaneetha K P, Shankar S. Tensile and flex-ural properties of snake grass natural fiber reinforced isophthallic polyestercomposites. Composites Science and Technology, 2012, 72, 1183-1190.

[40] Saravanan S S, Kumaravel A, Nagarajan T, Ganeshamoorthy I. Effect of chemical treatments on physicochemical properties of prosopis juliflora fibers. International Journal of Polymer Analysis and Characterization, 2014, 19, 383-390.

[41] Arthanarieswaran V P, Kumaravel A, Saravanakumar S S. Characterization of new natural cellulosic fiber from Acacia leucophloea bark. International Journal of Polymer Analysis and Characterization, 2015, 20, 367-376.

[42] Jayaramudu J, Guduri B, Varada R A. Characterization of new natural cellulosic fabric grewia tilifolia. Carbohydrate Polymers, 2010, 79, 847-851.

[43] Morvan C, Jauneau A, Flaman A, Millet J, Demarty M. Degradation of flax polysaccharides with purified endo-polygalacturonase. Carbohydrate Polymers, 1990, 13, 149-163.

[44] $\mathrm{Ku} \mathrm{H}$, Wang H, Pattarachaiyakoop N, Trada M. A review on the tensileproperties of natural fiber reinforced polymer composites. Composites Part B: Engineering, 2011, 42, 856-873.

[45] Rao S S, Jeyapal S, Rajiv S. Biodegradable electro spun nano composite fibers based on poly (2-Hydroxy Ethyl Methacrylate) and bamboo cellulose. Composites Part B: Engineering, 2014, 60, 43-48.

[46] Charlet K, Eve S, Jernot J P, Gomina M, Breard J. Tensile deformationof a flax fiber. Procedia Engineering, 2009, 1, 233-236. 
[47] Rong M Z, Zhang M Q, Liu Y, Yang G C, Zheng H M. The effect of fiber treatment on the mechanical properties of unidirectional sisal reinforced epoxy composites. Composites Science and Technology, 2001, 61, 1437-1447.

[48] Satyanarayana K G, Guimaraes J L, Wypych F. Studies on lingocellulosic fibers of Brazil. Part I: Source production, morphology, properties and applications. Composites Part A: Applied Science and Manufacturing, 2007, 38, 1694-1709.

[49] Silva R V, Spineli D, Bose F W W, Claro N S, Chierice G O, Tarpani J R. Fracture toughness of natural fibers/castor oil polyurethane composites. Composites Science and Technology, 2006, 66, 1328-1335.

[50] Singha A S, Thakur V K. Mechanical, morphological and thermal properties of pine needle-reinforced polymer composites. International Journal of Polymeric Materials and Polymeric Biomaterials, 2009, 58, 21-31. 


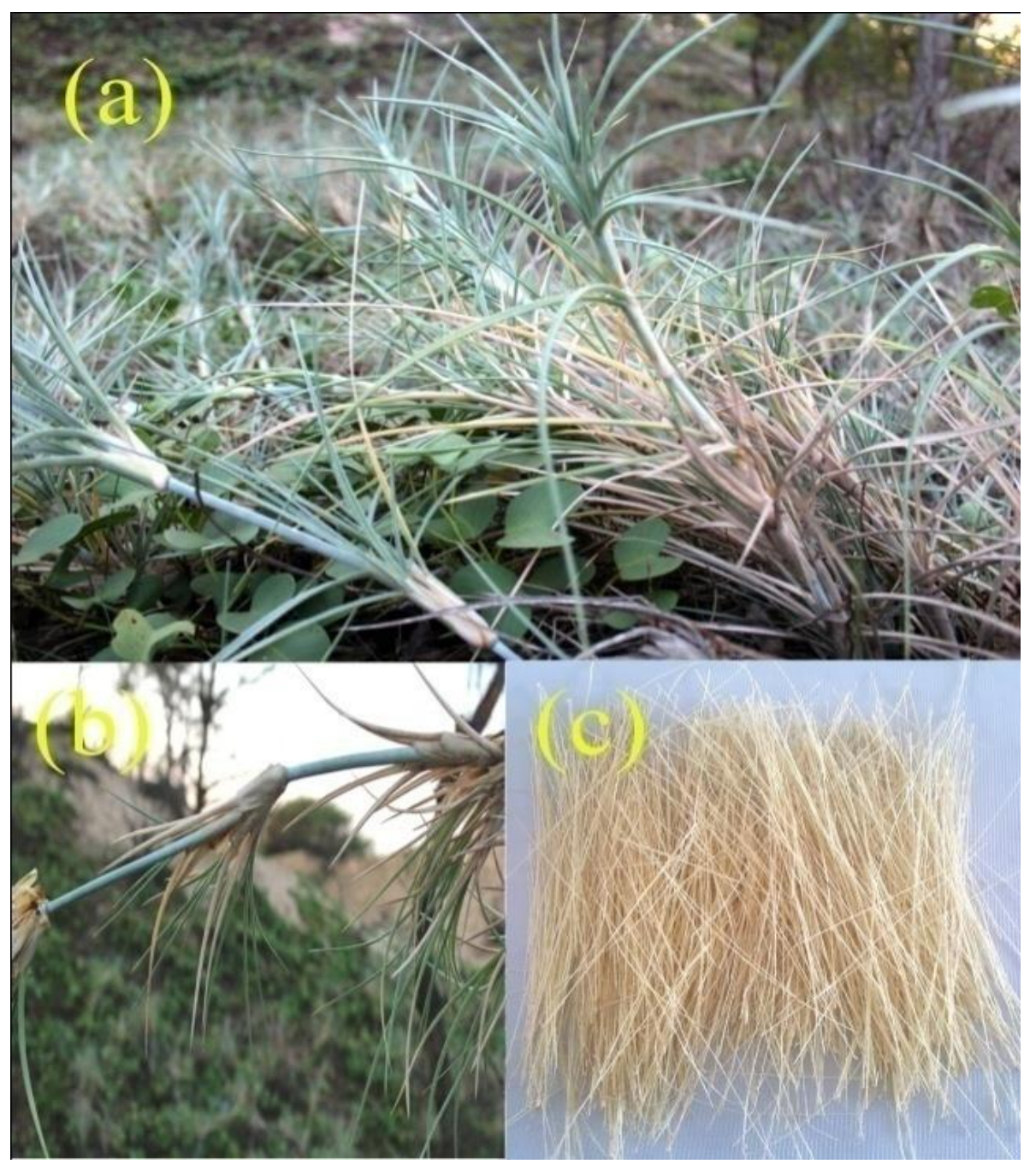

Fig. 1 (a) Spinifex littoreus plant (b) stem (c) extracted fiber

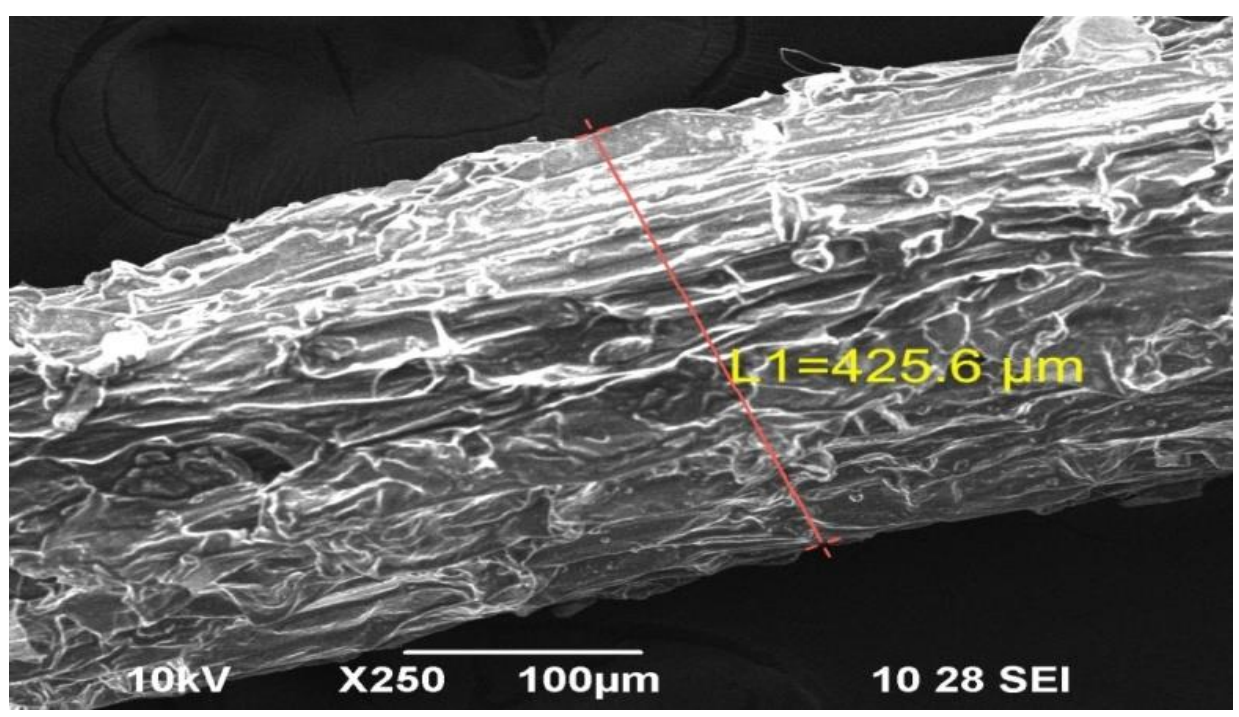

Fig. 2 SEM micrograph of raw Spinifex littoreus fiber surfaces 

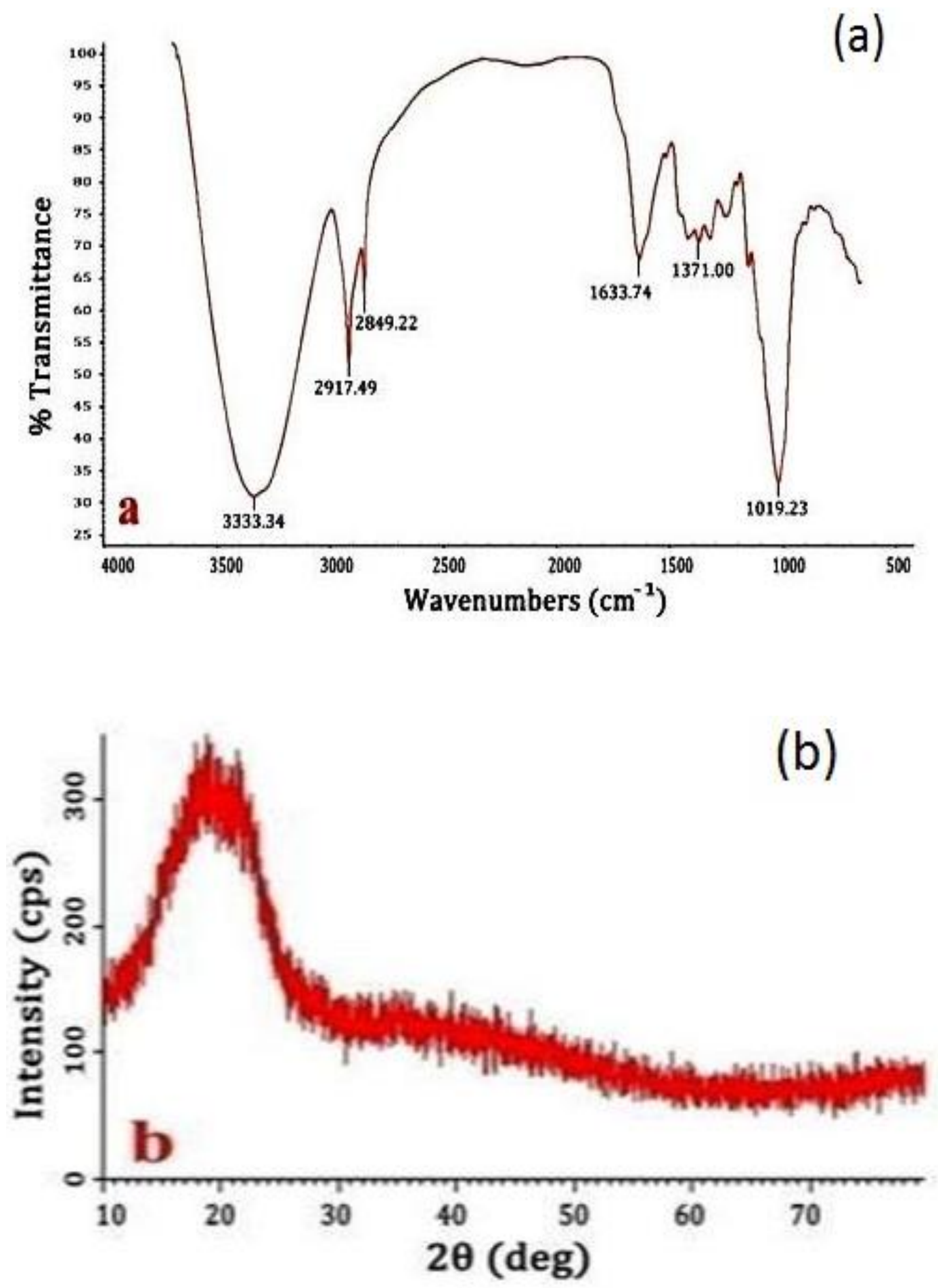

Fig. 3 (a) FTIR and (b) XRD spectrum of the SLF 


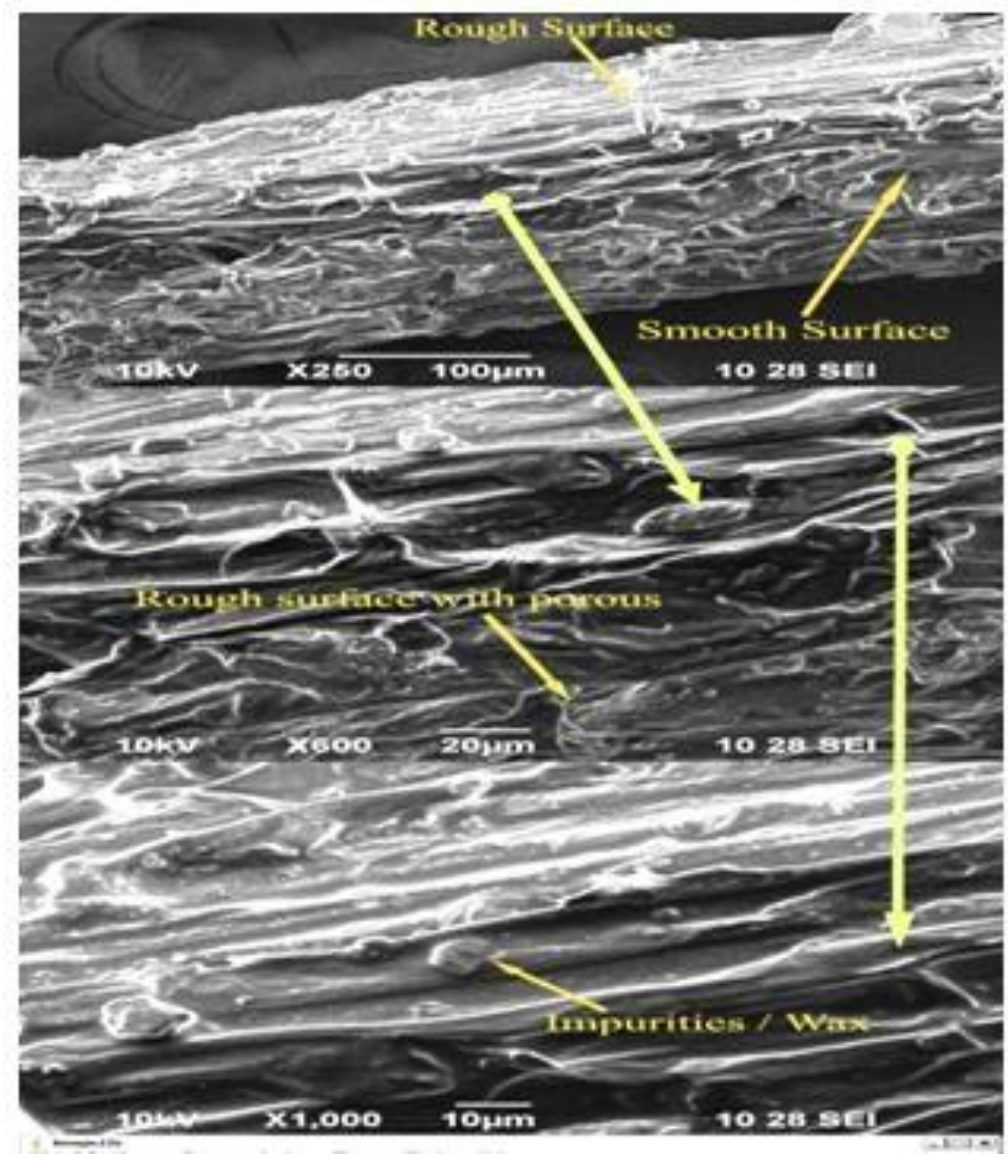

Fig. 4 Surface morphology of the Spinifex littoreus fiber from SEM

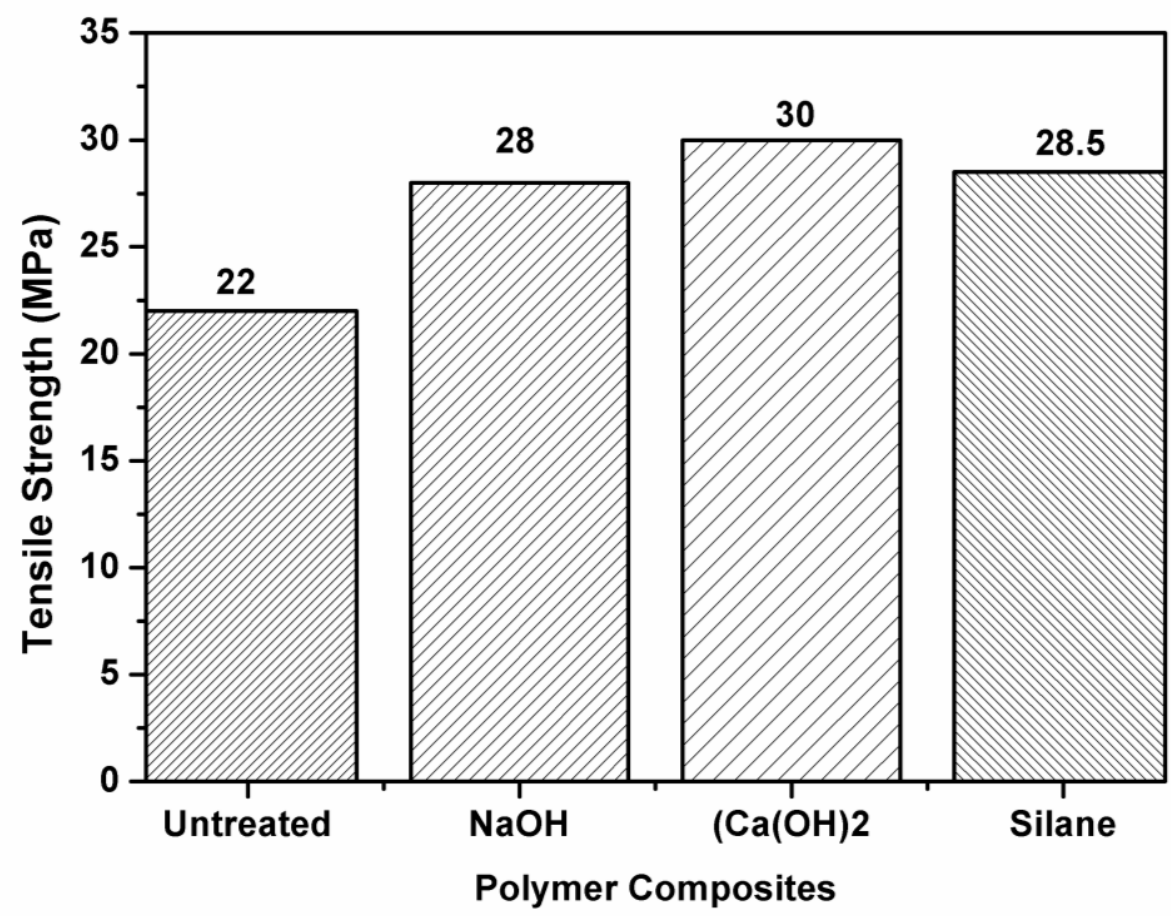

Fig. 5 Tensile properties of short SLF/polyester composites 

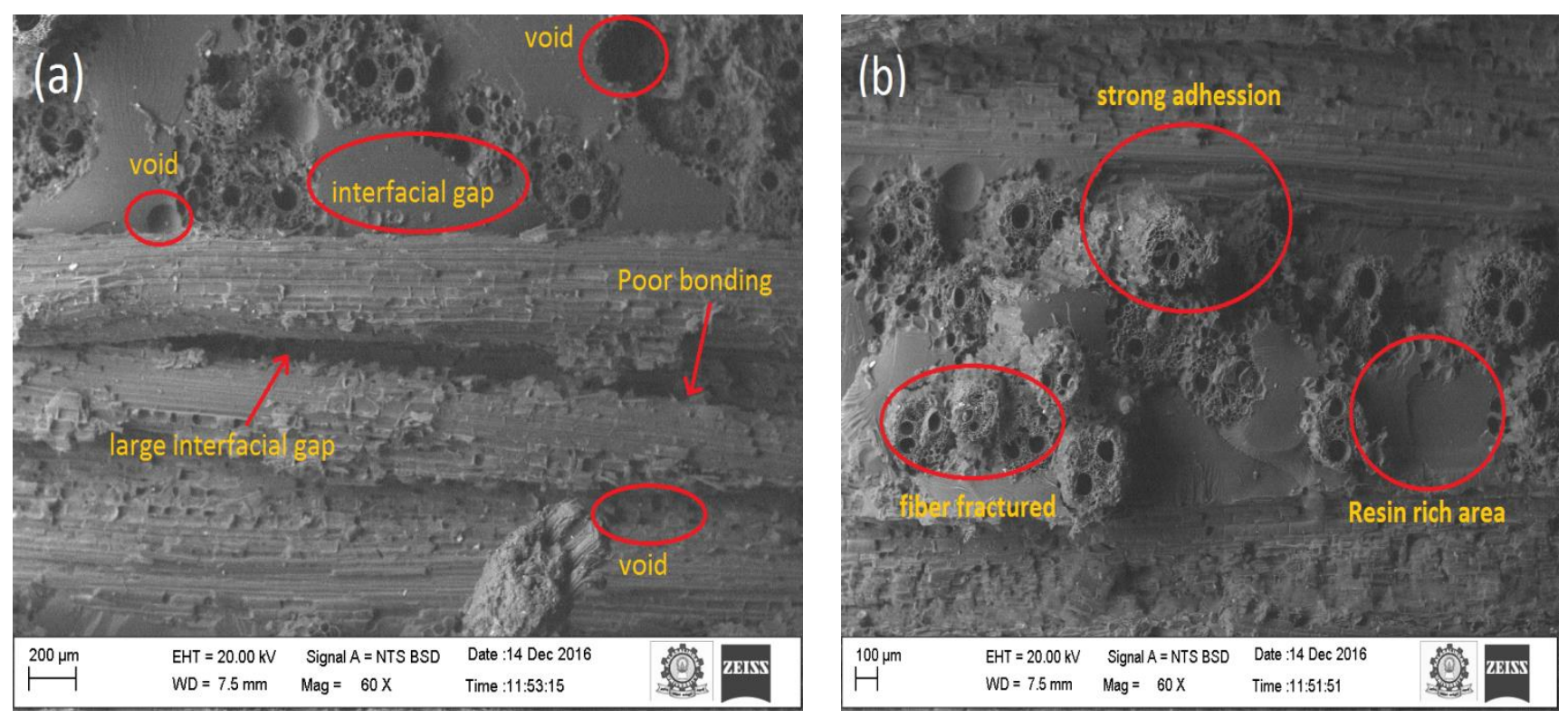

Fig. 6 Tensile micrograph of the Spinifex littoreus/polyester composite (a) untreated and (b) $\mathrm{Ca}(\mathrm{OH})_{2}$ treated SLF/polyester composite

Table1 Mechanical properties of Spinifex littoreus fiber

\begin{tabular}{ccccc}
\hline $\begin{array}{c}\text { Gauge length } \\
(\mathrm{mm})\end{array}$ & $\begin{array}{c}\text { Tensile } \\
\text { strength } \\
(\mathrm{MPa})\end{array}$ & $\begin{array}{c}\text { Young's } \\
\text { modulus } \\
(\mathrm{GPa})\end{array}$ & $\begin{array}{c}\text { Strain to } \\
\text { Failure } \\
(\%)\end{array}$ & $\begin{array}{c}\text { Diameter } \\
(\mathrm{mm})\end{array}$ \\
\hline 10 & 211 & 3.33 & 9 & 0.42 \\
20 & 231 & 2.5 & 8 & 0.41 \\
30 & 263 & 4.12 & 6 & 0.40 \\
40 & 336 & 7 & 5 & 0.42 \\
\hline
\end{tabular}

